\title{
Road accessibility and articulation of metropolitan spatial structures: the case of Madrid (Spain)
}

\author{
Héctor S. Martínez Sánchez-Mateos ${ }^{\mathrm{a}, *}$, Inmaculada Mohíno Sanz ${ }^{\mathrm{b}}$, José M Ureña Francés ${ }^{\mathrm{b}}$, \\ Eloy Solís Trapero ${ }^{\mathrm{b}}$ \\ ${ }^{a}$ Universidad de Castilla-La Mancha, Facultad de Letras, Avenida Camilo Jose Cela s/n, 13071 Ciudad Real, Spain

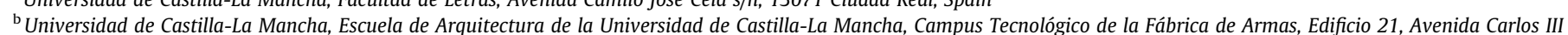 \\ s/n, 45071 Toledo, Spain
}

\section{A R T I C L E I N F O}

\section{Keywords:}

Urban network

Accessibility

Polycentrism

Madrid

Spain

\begin{abstract}
A B S T R A C T
In the last few decades, rapid growth in mobility has facilitated the inclusion of distant places in metropolitan processes and the modification of traditional metropolitan areas into Polycentric Urban Regions. This paper aims to understand the articulation of metropolitan urban regions through a diachronic road network accessibility analysis with a focus on the Madrid Metropolitan Region (Spain) over a period of general increase in accessibility. The findings reveal that the metropolitan core has been reinforced and that its influence area has expanded. However, the main contribution of this work is the proposal of a methodological approach to identify city-profiles among the sub-centres organising the emerging polycentric urban structures.
\end{abstract}

(c) 2014 Elsevier Ltd. All rights reserved.

\section{Introduction}

Changes in urban systems have occurred in recent decades at different spatial levels (Anas et al., 1998; van der Laan, 1998). Aiming to identify the features of emerging urban forms and the driving forces of these spatial changes, many scholars have already studied the transformation of metropolitan areas from monocentric to polycentric (Lee, 2007).

Although these metropolitan changes vary among regions in developed economies, in the last few decades, the general trends can be summarised by an increase in their catchment area, covering a wider territory, and a re-location of population and economic activities within the metropolitan boundaries, generating polynuclear urban structures (see Fig. 1).

From a spatial perspective, the debate regarding the evolution of metropolitan regions is closely related to transport developments (Helbich and Leitner, 2009) especially roads and highway systems (Baum-Snow, 2007). This undeniable relationship between transport and metropolitan change has been extensively studied from many points of view: (a) the scale shift and enhancement of externality, progressively integrating wider areas; (b) the

\footnotetext{
* Corresponding author. Tel.: +34 9262953006865.

E-mail addresses: Hectors.martinez@uclm.es (H.S. Martínez Sánchez-Mateos), Inmaculada.mohino@uclm.es (I.M. Sanz), Josemaria.urena@uclm.es (J.M.U. Francés), Eloy.solis@uclm.es (E.S. Trapero).
}

settlement structure transformation, with phenomena like urban sprawl and re-location of economic activities; (c) the evolution of the internal functional relations, mainly derived from the increasing interaction within urban networks; (d) the new economic patterns resulting from specialisation and complementary processes; and (e) the application of more rational principles for land-use planning and decision-making (governance).

In this context, the relationship between urban structures, transport networks and accessibility has been positioned at the heart of different discourses about growth, cohesion, sustainability (EC, 1999; Gordon and Richardson, 1996; Scott et al., 2001; Horner, 2004; Sohn, 2005), decentralisation and core-periphery relations (Meijers et al., 2012). Moreover, accessibility has been used as a tool for exploring and describing complex metropolitan structures (Giuliano et al., 2012) that rely on the identification of employment sub-centres, as originally proposed by Giuliano and Small (1993). In addition, other empirical approaches have used flow analyses to unravel polycentric structures (Clark and Kuijpers-Linde, 1994; van der Laan, 1998; Limtanakool et al., 2007).

However, whilst transport networks are better characterised as facilitators, a complex set of economic and urban factors are causing or fostering these structural transformations. From a social perspective, transport allows increasing commuting and migration levels and facilitates population and economic growth by raising the opportunities for spatial contact (Anas et al., 1998; Kloosterman and Musterd, 2001; Schwanen et al., 2001). Other 


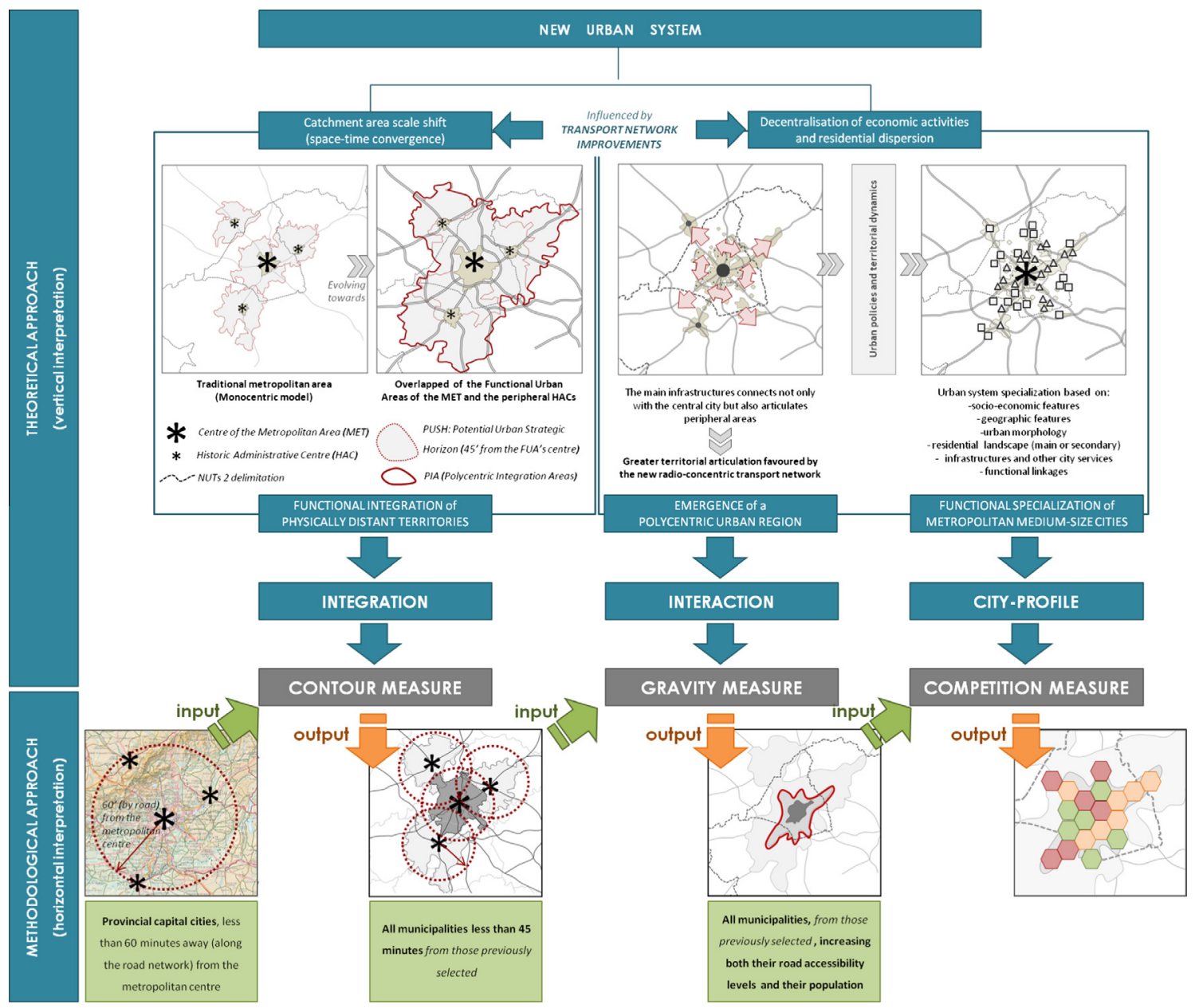

Fig. 1. Theoretical scope.

social aspects such as the share of part-time jobs, car use or transportation cost levels (Zheng, 1991; Le Néchet, 2012) also highlight the role of transport. Similarly, different economic factors have been identified, in advanced economies, as the causes of metropolitan evolution, such as changes: in the structure of economic activities (i.e., concentration or specialisation patterns), in the production structure and location, or in the share of economic activities (influenced by the spread of the use of ICT and the increasing importance of services and knowledge sectors) (Fujita and Ogawa, 1982; Krugman and Venables, 1996; Bogart and Ferry, 1999; Lee, 2007; Garcia-López and Muñiz, 2010).

Nevertheless, the work presented in this paper does not intend to examine the driving forces that give rise to new metropolitan structures but to understand the influence of road networks in facilitating metropolitan processes. More specifically, focused on a morphological analysis, the aim of this paper is to determine to what extent road accessibility analyses are appropriate in describing changes in metropolitan spatial structure (Giuliano et al., 2012).

The analysis carried out in this paper is developed for the Madrid Urban Region which has rapidly developed from a compact urban pattern towards a more sprawling one, showing an expansion process in the last few decades (del Cin et al., 1994). This spatial growth can be contextualised and analysed together with its transport network growth, included in the 1984-2008 Spanish transport policy. Hence, since the late 1970s Madrid evolved from a centralised metropolitan area towards a polycentric metropolitan region (Heitkamp, 2000). The two time scenarios of 1981 and 2011 are chosen according to the corresponding Census data. Despite the fact that public transport plays a crucial role within the traditional metropolitan area (up to $40-50 \mathrm{~km}$ from the metropolis), this study focuses only on the road network. This is because the share of private car in medium-distance travel (over $50 \mathrm{~km}$ ) was $78 \%$ in 2007 (Fomento, 2007).

The paper is set out as follows: Section 2 builds on the theoretical approach, connecting spatial accessibility analyses and recent transformations of urban systems. This is followed by the proposed methodology in Section 3, which describes the proposed accessibility model. Section 4 defines and characterises the case study; followed by Section 5 which gathers the main results and outcomes. The last section summarises and discusses the research conclusions.

\section{Theoretical background: accessibility and polycentric urban structures}

The relationship between transport, accessibility and metropolitan spatial structure has acquired major relevance in literature and has been treated in different ways. This section proposes a perspective for exploring the influence of road accessibility in the urban system, fostering the gradual transformation of monocentric metropolitan areas.

\subsection{The analysis of Polycentric Urban Regions}

Polycentric patterns in urban systems have been recognised in different ways, and the notion of polycentrism has become polysemous, assuming mutual interaction as a key element (Green, 2007). 
These polycentric urban networks can be identified at two different scales: (a) intra-metropolitan polycentrism, as a result of the generation of new centres (Garreau, 1991; Richardson, 1988) and the reinforcement of the industrial poles of the first industrialisation process (Roca et al., 2012); and (b) supra-metropolitan polycentrism, as a result of the integration of new metropolitan regions, whether by coalescence of spaces in different provinces/regions, as in the Randstad (Netherlands) or Rhine-Rhur (Germany) (Hall and Pain, 2006; Kloosterman and Musterd, 2001; Meijers and Romein, 2003), or by the extension of the metropolitan influence over close systems of small and medium-sized cities (Roca et al., 2012; Solís et al., 2014).

Two main approaches have been used to measure urban polycentrism: morphological and functional. The morphological approach is based on identifying nodes and characterising them in terms of size and complementarities to other nodes (see the seminal work by Giuliano and Small, 1993). The functional approach is based on characterising centres by their interconnecting flows. Different types of flow are used, such as daily commuting, business and leisure travel and also intra-metropolitan migration (Limtanakool et al., 2009). This paper uses the morphological approach, setting out the appropriateness of accessibility as a proxy to interpret the urban network and the potential for spatial integration (Fig. 1).

Improvements in transport systems (infrastructures and services) have relevant implications for spatial structures and functional relationships. First, better communication systems diminish time distances, bringing distant territories closer together (a phenomenon known as time-space convergence, (Spiekermann and Wegener, 1994)), and expanding potential catchment areas (spreading effects). The general increase in individual mobility over the last decades has allowed an important scale shift, integrating larger areas and extending the concept of Functional Urban Areas (FUAs) to that of Polycentric Integration Areas (PIAs) (ESPON, 2004). Second, economic activities decentralisation and residential dispersion, supported by new transport networks, may lead to the appearance of new centres in metropolitan peripheral locations, taking advantage of high accessibility levels, closeness to the centre and lower land prices. Both aspects, expansion and new relations within metropolitan regions, suggest the emergence of polycentric spatial structures. However, in formal terms, functionality and integration show that centrality still matters and that interaction is beyond morphological aspects, as van Oort et al. (2010) proved in the Randstad. Taking this into consideration, there are three main questions connecting metropolitan spatial structure and road system:

(a) Integration: Road network improvements facilitate a scale shift in the settlement system, increasing the daily reachable spaces and nuclei. Hence, what is the spatial extent of the metropolitan centre and sub-centres influences'?

(b) Interaction: Road transport reinforces agglomeration economies and makes possible the urban economies of proximity (this can also be interpreted as a measure of centrality). Therefore, what is the potential of mutual interaction within extensive metropolitan areas?

(c) City-profile: Accessibility improvements help cities to acquire competitive advantages and define potential locations for workers and/or jobs. Thus, are these changes in extension and interaction affecting the main roles of metropolitan centres? And, how are the sub-centres participating of the subsequent structure?

\subsection{The accessibility analysis of urban networks}

Accessibility is often used to explore metropolitan relations and urban networks. In this context, accessibility has been used as a reliable empirical concept to relate urban structures and jobs/ housing locations (Horner, 2004). Progressively, longer commuting distances allow greater separation between housing and workplaces, giving way to the spreading effect and triggering other related effects that allow the appearance of nearby sub-centres (Solís et al., 2012). As a result, contrary to the traditional mobility patterns of movements directed from the periphery to the centre, mobility has become more heterogeneous and polynodal, including flows from periphery to periphery and from centre to periphery (van der Laan, 1998).

Moreover, road network improvements have allowed a scale shift of the traditional metropolitan area, extending its boundaries (Baum-Snow, 2007; Rodrigue et al., 2009; Garcia-López, 2012), catalysing agglomeration and modifying inter-city relations as a consequence of new functional linkages among peripheral metropolitan municipalities. Accessibility measures are a component of numerous urban studies looking at the spatial organisation of urban systems (Harris, 2001): they have been applied to visualise aspects of urban morphology and location in economic systems (Cheng et al., 2013) and urban flows distribution (Patuelli et al., 2007; Reggiani et al., 2011). In any case, the key factor that enables the use of accessibility at the urban level is its ability to visualise and analyse spatial processes.

One of the earliest measures applied to recognise urban spatial features is the cumulative opportunity or contour measure (Ingram, 1971; Vickerman, 1974). The contour measure can be used to define catchment areas by determining their limits within certain travel times or distances from a node, assessing the number of opportunities that can be reached within each time or distance threshold.

Among the existing literature, studies considering accessibility as a facilitator for spatial interaction are relatively frequent (Hansen, 1959; Wilson, 1967; Morris et al., 1979). Several studies have focused on potential accessibility measures, which have been profusely used to depict and describe spatial configurations. Recent examples highlight their usefulness to acknowledge the influence of accessibility in shaping urban networks (Cheng et al., 2013) and relations through different approaches such as commuting flows in extensive urban areas (Sohn, 2005; van Oort et al., 2010), or the market potential of workplaces and labour with a regional scope (López et al., 2008; Condeço-Melhorado et al., 2011).

In some cases, these models achieve great complexity, assuming a certain capability to embed heterogeneous components (van Wee et al., 2001). Several authors have adapted potential accessibility measures to include competition effects which affect spatial modelling and location patterns (Eiselt and Laporte, 1989), distorting the results of potential measures. For example, Joseph and Bantock (1982) analyse accessibility where competition only takes place in destinations. Others ground competition in origins by dividing the available opportunities at origin $i$ by the potential demand from $i$ (Weibull, 1976; van Wee et al., 2001). A third group considers competition at both origins and destinations based on the balancing factors of Wilson's double constrained spatial interaction model (Horner, 2004; Patuelli et al., 2007).

\section{The empirical model: assessing accessibility patterns}

The methodology proposed in this paper is based on a combination of complementary road network accessibility indicators for two time scenarios (1981 and 2011). The method is built for a better understanding of the spatial structure and dynamics of urban regions, given the capability of accessibility to embed spatial structures and their relationship with urban networks at several scales (Geurs and van Wee, 2004; Horner, 2004). This approach combines 
three different indicators to acknowledge different components of the metropolitan spatial structure (Fig. 1 and Table 1).

The reason why three combined accessibility measures are used is twofold:

- First, since there is a specific interpretation for each measure, related to aspects of the metropolitan region spatial structure (vertical reading, see Fig. 1): (a) the extension and growth of the urban interaction area is measured by a contour indicator; (b) the potential for interaction within the urban region is described by a potential indicator; and (c) the role and performance of sub-centres in polycentric metropolitan regions is evaluated by a competition indicator.

- Second, the three aforementioned steps are actually a sequence, because the output of each measure becomes the input of the subsequent one, delimitating the area to which each measure is applied (horizontal link among measures). The results of the contour indicator are the sample involved in the analysis of potential accessibility, and the main centres organising the metropolitan regions identified by applying this second indicator are further analysed by the competition one. This means that the latter indicators partially include results of the previous analyses (horizontal reading, see Fig. 1).

The model is set in a GIS geodatabase including information of municipalities and roads, and fed by two data sources, both at municipal level: (a) number of available jobs from Social Security sources (obtained under request), and (b) number of workers from the Spanish Official Statistics Institute (INE) website.

Travel time is calculated by computing the road network in GIS. In order to do this, four road types are identified (motorway, conventional road, urban artery and city street), assigning to each one a maximum speed according to the existing standard at each time scenario: 1981 (100, 70, 40 and $30 \mathrm{~km} / \mathrm{h}$ ) and 2011 (adding $10 \mathrm{~km} /$ $\mathrm{h}$ more). In addition, each road stretch is qualified in order to model this maximum speed to capture congestion at specific stretches: (a) $80 \%$ speed reduction at road crossings, (b) $30 \mathrm{~km} / \mathrm{h}$ along local streets connecting each city with the road network, and (c) estimated speed based on congestion levels in some metropolitan roads (as assessed by Abadía and Pineda, 2009: 17).
Once the GIS database is built, the model is able to produce results following the sequence of accessibility measures that are intended to explore successive urban network components (Table 1).

\subsection{The contour measure}

The contour measure provides evidence of the spatial scale expansion of urban regions over the years by the increasing number of municipalities, people and jobs that can be reached within certain time budgets.

This contour measure is formulated (Eq. (1) in Table 1) as an expression depending on a Boolean function (being 1 if zone $j$ is within the time threshold and 0 otherwise) and on the number of opportunities in zone $j$. The wide variety of travel time budgets considered in the literature demonstrates the difficulty of establishing a unique value which greatly varies from country to country (Cerdá, 2009; Kawabata, 2009; Curtis and Scheurer, 2010; Reggiani et al., 2011). Nevertheless, an ESPON (European Spatial Planning Observation Network) report delimitates FUAs throughout the European Union considering the reachable area from each centre by car, based on the hypothesis that commuting flows occur predominantly within a 45 min time budget (ESPON, 2004).

Whilst this indicator incorporates land use patterns and infrastructure constraints and is easy to interpret, it has some theoretical shortcomings. First, the results greatly vary depending on the time budget considered. Second, it does not account for the size of the facilities (attractiveness) or the cost of reaching them. Finally, it does not take into account a distance-decay function to weight the opportunities. For these reasons, the area delimited by a travel time budget value should only be considered as a potential interaction catchment area. Two thresholds are used in this paper: $45 \mathrm{~min}$ to define the external contour of the metropolitan region, and $30 \mathrm{~min}$ to define proximity effects more accurately.

Results are useful in two ways: (1) they define the area in terms of proximity and probability, plotting the maximum extent of each FUA and setting the final sample of municipalities within the given time distance in the 2011 scenario (the maximum possible sample); and (2) they allow defining inner/smaller time threshold contours to characterise different interaction probabilities and proximity ranges.

Table 1

Summary of the accessibility analysis sequence followed in the empirical application.

\begin{tabular}{|c|c|c|c|c|}
\hline Component & Indicator & Formulation & Variables & Data \\
\hline \multirow[t]{2}{*}{ Integration } & $\begin{array}{l}\text { Contour } \\
\text { measure }\end{array}$ & $A_{i}=\sum_{j=1}^{J} B_{j} \cdot O_{j}(1)$ & $t$ : threshold/time budget & - GIS road network \\
\hline & & $\begin{array}{l}B_{j}=1 \text { if zone } j \text { is within the } \\
\text { predetermined threshold } t \\
0 \text {, otherwise }\end{array}$ & $O_{j}$ : opportunities in zone $j$ (population and jobs) & $\begin{array}{l}\text { - Population register, } \\
2010 \\
\text { - Workplaces, } 2011\end{array}$ \\
\hline \multirow[t]{2}{*}{$\begin{array}{l}\text { Centrality } \\
\text { interaction }\end{array}$} & $\begin{array}{l}\text { Potential } \\
\text { measure }\end{array}$ & $A P_{I}=\sum_{j} P_{j} * f\left(d_{i j}\right)(2)$ & $P_{j}:$ jobs located in destination $j$ & - Workplaces, 1981 \\
\hline & & Impedance function: $f\left(d_{i j}\right)=e^{-\beta * t_{i j}}$ (3) & $\begin{array}{l}t_{i j}: \text { travel time between } i \text { and } j \text { by road (minutes) } \\
\beta \text { : parameter }\end{array}$ & $\begin{array}{l}\text { - GIS road network } \\
\text { - Set to } 1 \text { in this analysis }\end{array}$ \\
\hline \multirow[t]{5}{*}{ Trends } & $\begin{array}{l}\text { Competition } \\
\text { measure }\end{array}$ & $A_{i}\left[\sum_{j} E_{j} / B_{j} \cdot f\left(d_{i j}\right)\right]^{-1}(4)$ & $A_{i}, B_{j}:$ accessibility indexes & $\begin{array}{l}\text { - Population registers, } \\
1981 \text { and } 2010\end{array}$ \\
\hline & & $B_{j}\left[\sum_{i} E_{i} / B_{i} \cdot f\left(d_{i j}\right)\right]^{-1}(5)$ & $\begin{array}{l}E_{j} \text { : attraction factor of zone } j \text { for trips originated in zone } i \\
\text { (number of jobs) }\end{array}$ & $\begin{array}{l}\text { - Workplaces, } 1981 \text { and } \\
2011\end{array}$ \\
\hline & & & $\begin{array}{l}O_{i} \text { : repulsion factor of zone } i \text { for trips with destination in zone } \\
j \text { (number of job seekers) }\end{array}$ & $\begin{array}{l}\text { - GIS road network } \\
(1981-2011)\end{array}$ \\
\hline & & & $\begin{array}{l}f\left(d_{i j}\right) \text { : impedance function (depending on travel time between } \\
i \text { and } j \text { by road) }\end{array}$ & - Set to 1 in this analysis \\
\hline & & & $\beta:$ parameter & \\
\hline
\end{tabular}

(1) Cerdá (2009: 7).

(2) Geurs and van Wee (2004: 133).

(3) Reggiani et al. (2011: 532).

(4) and (5) Willigers et al. (2003: 9). 


\subsection{The potential accessibility in urban networks}

Once the extension of the metropolitan region has been defined, the second step applies the potential accessibility measure to the resultant sample. The potential accessibility expression used in this paper considers two factors (Eq. (2) in Table 1): attraction caused by available jobs and friction of distance by travel time incorporated as a power-decay function. Results show that each location $i$ interacts with other locations $j$ due to the local labour market attraction. Besides, this measure allows the evaluation of centrality since the resulting hierarchy shows the relative attractiveness of each location.

The use of such indicators is revealed as the best possible combination of accuracy and efficiency in terms of data requirements and result readability (Geurs and van Wee, 2004). However, the main limitation of potential accessibility measures is that they do not consider competition effects and temporal constraints. Moreover, their use implies that the demand for opportunities is uniformly distributed across space and/or that these opportunities have no capacity limitations (Cerdá, 2009).

This second step aims to analyse potential accessibility changes between 1981 and 2011. However, the use of two different time scenarios generates an endogeneity problem derived from the causal relation between transport improvements and population growth. In this sense, it is almost impossible to determine whether the accessibility gain is due to the first or the latter factor (López et al., 2008). A possible solution is making one variable timeinvariant, avoiding causality between variables (Baum-Snow, 2007; Garcia-López, 2012). In our analysis, jobs are fixed to the situation in 1981 in Eq. (2) (Table 1) and travel time varies for both network-scenarios (1981 and 2011) to partially address this shortcoming.

This procedure assesses the road infrastructure role in the distribution of accessibility beyond location changes and population growth. Nevertheless, in order to add a perspective on population and its changes, the paper also proposes a typology of municipalities according to the evolution on potential accessibility and demographic change between 1981 and 2011.

\subsection{The evaluation of competition}

Lastly, competition is included: first, to address the problem of gravity models in samples where locations can serve as both time origins and destinations, and second, to add a new insight to the previous interpretation, by characterising (only) the best performing poles (metropolitan sub-centres) in the potential accessibility measure, since they have the highest potential roles in organising metropolitan regions.

This paper accounts for such competition effects based on the balancing factors of Wilson's double constrained spatial interaction model, bearing in mind that competition exists both at origins and destinations. The most important advantage of this model is precisely this two-way consideration, providing more realistic accessibility estimations. However, its main disadvantage is the difficulty for estimation, interpretation and communication (Geurs and Ritsema van Eck, 2001). Therefore, this approach facilitates the description of each zone with two accessibility values, understood as the effort (for residents/potential employees of each zone) to access (the jobs of) the rest of the sample $\left(A_{i}\right)$ and the ease (of the jobs) for being accessed by the potential workers of the whole sample $\left(B_{j}\right)$.

This measure is formulated as two mutually dependent expressions (Eqs. (4) and (5); Table 1) which have to be obtained iteratively until the model reaches equilibrium. Moreover, the first indicator $\left(A_{i}\right)$ is directly dependent on an attraction factor $\left(E_{j}\right)$ of zone $j$ for trips generated at zone $i$ and the second one $\left(B_{j}\right)$ is directly proportional to a repulsion factor $\left(O_{i}\right)$ of zone $i$ for trips with destinations in this zone. Similarly to the potential accessibility measure, the two expressions are dependent on an impedance function, $f\left(d_{i j}\right)$ (Willigers et al., 2003).

The aim of this measure is to provide an accurate characterisation of the main centres organising the metropolitan region since each sub-centre has followed different trajectories giving rise to different city-profiles among Polycentric Urban Regions. In this manner, the current urban structure is a result of an interdependent relationship between transport (road) network improvements and residences/workplaces locations (that is to say, road improvements may influence population/jobs relocations but also an increase of jobs or population in a given location may lead to road improvements due to increased travel demand). Therefore, the competition measure formulation takes into account the variation of both travel cost and attraction factors for each time scenario in order to better capture the urban network complexity.

\section{Study area}

The accessibility model is applied to the Madrid Urban Region over the last three decades. During this period, both a regional urban spatial reconfiguration and a noteworthy road network change took place (Fig. 2). This change was caused first, by the transformation of radial roads into motorways and duplicating radial motorways in several corridors (northeast, southeast, south and southwest). Second, by the creation of two orbital motorways (M-30 and M-40) around and close to Madrid and also two semiorbital ones (M-45 and M-50) along the west-south-northeast sectors and slightly further away from the centre $(5-10 \mathrm{~km}$ the first two and $10-15 \mathrm{~km}$ the latter). Lastly, by the creation of a tangential motorway from Toledo towards the southeast (CM-42). The resulting transport network morphology allows primarily radial relations with the centre and secondarily tangential connections.

Gutiérrez and Gómez (1999) applied a potential accessibility analysis to the new orbital motorways around Madrid and predicted a tangential effect because they had created one of the densest radio-concentric networks in Spain. Their conclusions started to plot the forthcoming meshing of the road network and progressive integration of the urban network. At a national scale, Holl (2007) evaluated accessibility improvements due to the 19802000 Spanish motorway programme, showing how the main centre (Madrid) had concentrated accessibility and how considerable improvement occurred along all radial corridors.

Within this context, Madrid evolved towards an urban region with some daily functional relationships with the adjacent provinces of Guadalajara, Toledo and Segovia. The initial study area is set as the centre of the Madrid Urban Region and the three capital cities of the aforementioned contiguous provinces (Guadalajara, Segovia and Toledo).

Solís et al. (2014) stated that the emerging Madrid polycentric situation can be encapsulated as a network of medium-sized cities around Madrid (Fig. 2). This heterogeneous area is composed by numerous municipalities that take part in the whole system with different characteristics and integration levels.

\section{Results}

The results achieved can be summarised on three aspects. First, in terms of extension, the growth of the metropolitan region, overflowing beyond its traditional boundaries and reaching historic administrative cities. Second, in terms of urban structure, the change from a monocentric model towards a polycentric/dispersed one. Finally, in terms of urban system complexity, where each metropolitan sub-centre acquires different profiles. 

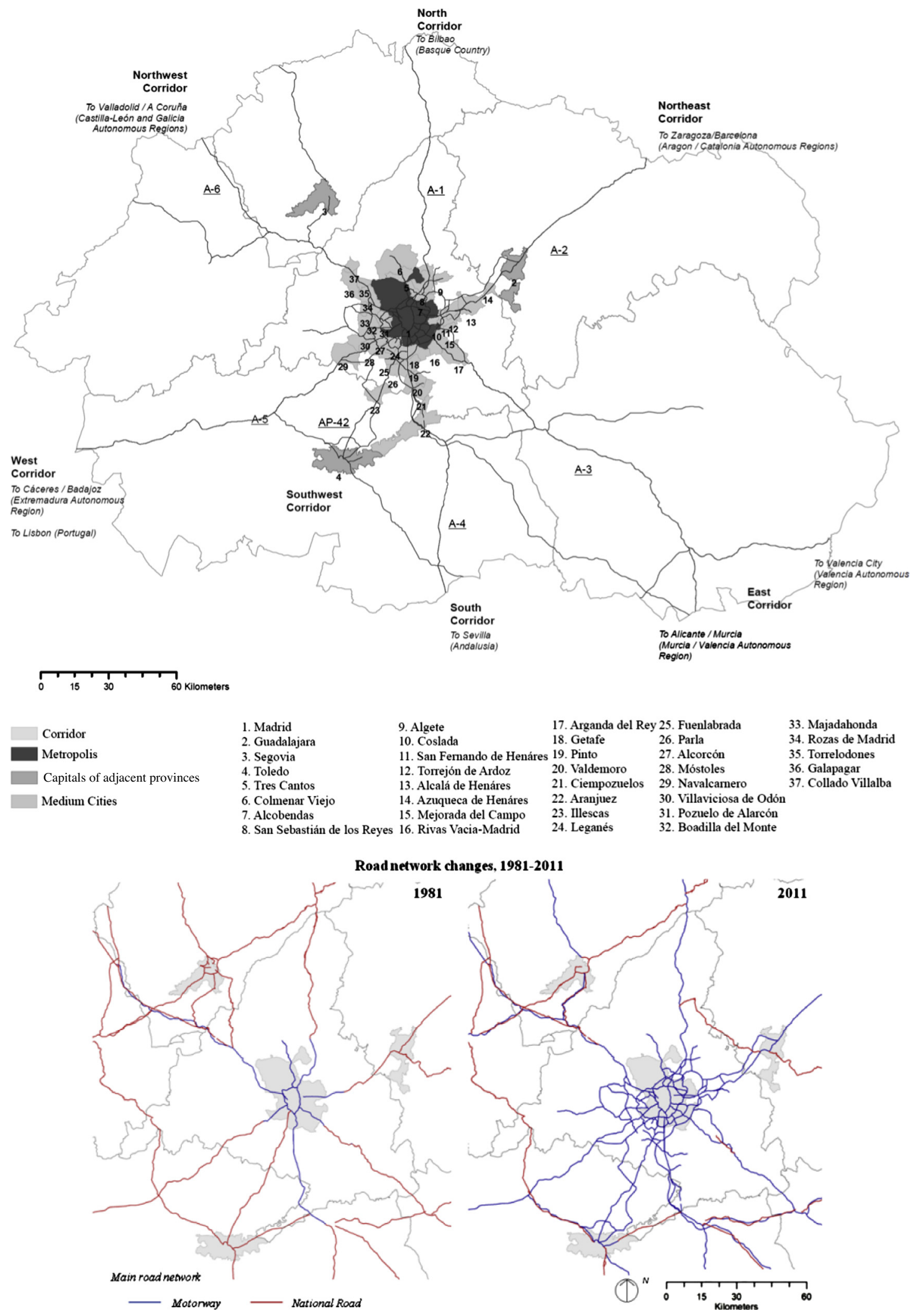

Fig. 2. Study area.

\subsection{The urban network: inclusion and extension}

The scale shift experienced by the metropolitan area is tackled by a contour measure, using 30 and 45 min travel time thresholds from Madrid and the respective capitals of the adjacent provinces of Guadalajara, Segovia and Toledo (Fig. 3).

As it could be expected, the reachable surfaces have increased and they considerably overlapped in 2011, especially those centred 


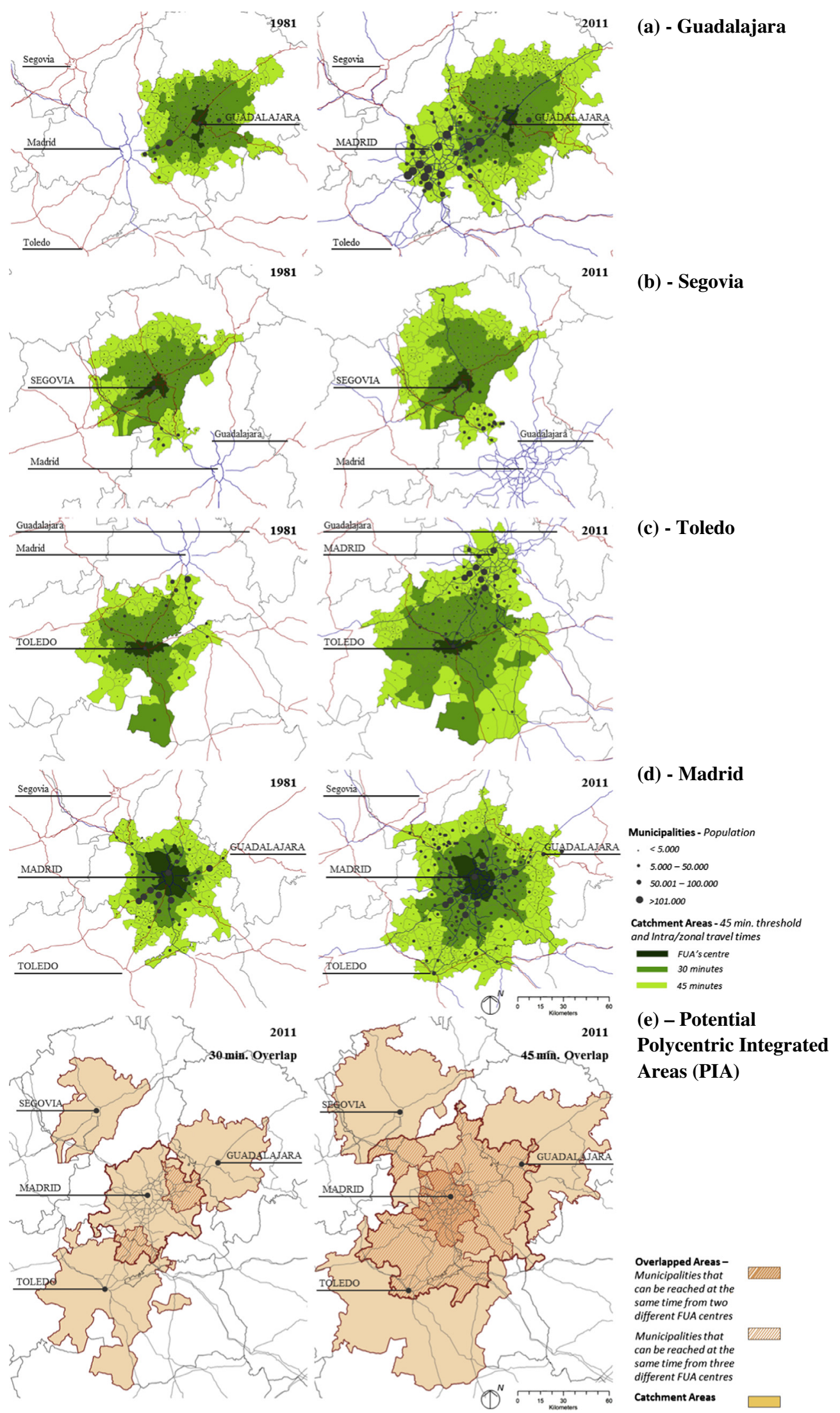

Fig. 3. Cumulative opportunity indicator: travel time thresholds. Years 1981-2011.

in Madrid, Toledo and Guadalajara (Fig. 3e). In 1981 the area accessible in 45 min from the centre of Madrid overflowed towards a small number of municipalities of the Toledo and Guadalajara adjacent provinces, not reaching their capitals. The accessible areas 
Table 2

Contour measure analysis, summary of results. Source: INE, Social Security and authors.

\begin{tabular}{|c|c|c|c|c|c|c|c|c|c|c|c|c|}
\hline \multirow{2}{*}{$\begin{array}{l}\text { FUA } \\
\text { YEAR }\end{array}$} & \multicolumn{3}{|l|}{ Toledo } & \multicolumn{3}{|c|}{ Guadalajara } & \multicolumn{3}{|l|}{ Segovia } & \multicolumn{3}{|l|}{ Madrid } \\
\hline & 1981 & 2011 & $\Delta 1981-2011$ & 1981 & 2011 & $\Delta 1981-2011$ & 1981 & 2011 & $\Delta 1981-2011$ & 1981 & 2011 & $\Delta 1981-2011$ \\
\hline \multicolumn{13}{|c|}{ Number of municipalities } \\
\hline$\leqslant 30^{\prime}$ & 56 & 88 & 32 & 44 & 105 & 61 & 57 & 74 & 17 & 24 & 78 & 54 \\
\hline $31^{\prime}-45^{\prime}$ & 52 & 73 & 21 & 69 & 121 & 52 & 64 & 64 & 0 & 78 & 130 & 52 \\
\hline \multicolumn{13}{|c|}{ Population (inhabitants) } \\
\hline$\leqslant 30^{\prime}$ & 150.093 & 579.163 & 429.070 & 333.478 & 811.352 & 477.874 & 81.442 & 111.928 & 30.486 & 4.271 .854 & 6.099 .211 & 1.827 .357 \\
\hline $31^{\prime}-45^{\prime}$ & 379.414 & 4.803 .978 & 4.424 .564 & 123.561 & 5.311 .719 & 5.188 .158 & 87.402 & 225.580 & 138.178 & 366.851 & 805.105 & 438.254 \\
\hline \multicolumn{13}{|c|}{ Number of jobs } \\
\hline$\leqslant 30^{\prime}$ & 42.360 & 209.323 & 166.963 & 93.650 & 307.752 & 214.102 & 23.228 & 32.548 & 9.320 & 1.285 .699 & 2.453 .237 & 1.167 .538 \\
\hline $31^{\prime}-45^{\prime}$ & 104.218 & 1.912 .889 & 1.808 .671 & 37.509 & 2.137 .842 & 2.100 .333 & 25.463 & 82.764 & 57.301 & 101.988 & 307.299 & 205.311 \\
\hline
\end{tabular}

Table 3

Potential accessibility analysis, summary of results. Source: INE, Authors.

\begin{tabular}{|c|c|c|c|c|c|c|c|}
\hline & Max & Min & Mean & S.D. & Moran's $i$ & $z$-Score & $P$ value \\
\hline 1981 & $1,346,200$ & 21079.3 & 52305.1 & 61328.5 & 0.1849691 & 17.400239 & 0.00000 \\
\hline 2011 & $1,369,500$ & 27647.7 & 68642.7 & 66922.8 & 0.301429 & 23.01616 & 0.00000 \\
\hline
\end{tabular}

from the centre of each provincial capital included parts of the Madrid administrative region/province, but none reached any other capital. In 2011, the wider territory accessible in $45 \mathrm{~min}$ from the centre of Madrid, reached the cities of Guadalajara and Toledo, and the same happened in reverse. However, none of the $45 \mathrm{~min}$ accessible areas centred in the three provincial capitals reached either of the other two. In 1981, only the 30 min accessible areas from the Madrid and Guadalajara centres slightly overlapped, while in 2011 they overlapped much more, as well as those from Madrid and Toledo (Fig. 3e).

The spatial shape of these enlargements demonstrates a coreperiphery pattern, growing in all directions from Madrid and asymmetrically from the other centres (Fig. 3d). The areas centred in Guadalajara and Toledo grew more towards Madrid (Fig. 3a and c), while in the case of Segovia (Fig. 3b) the growth towards Madrid was more limited, partially due to topographic restrictions.

Table 2 shows this spatial growth in terms of population and jobs within the thresholds. Madrid experienced a great increase in the number of habitants and jobs being accessible in the shorter (30 min) threshold because large adjacent municipalities grew closer, while Guadalajara and Toledo improved more in the longer (45 min) threshold due to the new found proximity to the larger municipalities. Segovia does not show much improvement in comparison to the others.

This means that Madrid better improves the population's access to jobs 30 min away when compared to the other three cities mentioned above; that Madrid, Guadalajara, Toledo and their intermediate areas increase their chances of becoming interweaved (reached from two cities); and that Madrid and its eastern and southern surrounding municipalities have the greatest potential of being reached from three cities.

\subsection{Measuring the potential for attraction and interaction}

The potential indicator shows a general increase of accessibility (Table 3). It is noticeable that the dispersion value increases during the study period and that the spatial correlation value increase is even greater (Moran's $i$ results). This demonstrates that accessibility improvements tend to concentrate in a few municipalities and are not generalised throughout the sample.

Locations with the highest potential accessibility levels are spatially clustered around the metropolitan centre in both scenarios, which is consistent with previous analyses (Gutiérrez and
Gómez, 1999; Holl, 2007). The year 2011 shows a more spread pattern than in 1981, but also concentrated from/to the centre, strengthening the advantages of central locations and reinforcing the lack of potential accessibility of the peripheral locations (Fig. 4a).

In 1981, locations sharing higher accessibility values were clustered in the first belt around Madrid, which may be interpreted as a limited number of places taking part in the metropolitan processes. The corridors of transport were taking shape at this time and there was only a southwestern cluster of sub-centres. In 2011 the situation was similar, but the number of sub-centres involved had slightly increased. Nevertheless, the northern corridors did not improve as much as the southern ones, probably because the development of new infrastructure started later on and was less dense than towards the south. In other words, in 2011 the lead taken by the southern belt was more visible.

Relative variation of accessibility (Fig. 4b) shows a spatial pattern of winning areas, which tend to be located in a periphery near the centre (Madrid), and polarising corridors southwards along the new radial axes. It also appears that a rough spread of accessibility increase follows some tangential motorways connecting the main radial ones.

The peripheral provincial capitals show different patterns, despite their similar distances to the metropolitan centre. It is also remarkable to point out that the limits set by the contour measure include distant places that show little capacity for interaction, demonstrating that the contour analysis probably overestimates the actual extension of the metropolitan influence and that the speed limits overestimates the actual range of distance covered by calculated travel times.

Once endogeneity has been partially addressed by fixing the number of jobs (as in 1981), population changes are also included in the analysis. Combining both accessibility and population evolutions, a three-typology classification is proposed (Fig. 4c): (a) leading poles as those municipalities that considerably gained in potential accessibility and population, (b) growing areas as those gaining considerably in potential accessibility but with comparatively smaller growth in population, and (c) areas without growth as those that did not gain considerably in either aspect.

In conclusion, a clear pattern can be identified, with leading poles located around Madrid (the most powerful ones within 25-30 km of Madrid) and along some radial corridors, reaching and including only the capitals of Guadalajara and Toledo (not 
(a) Potential Accessibility

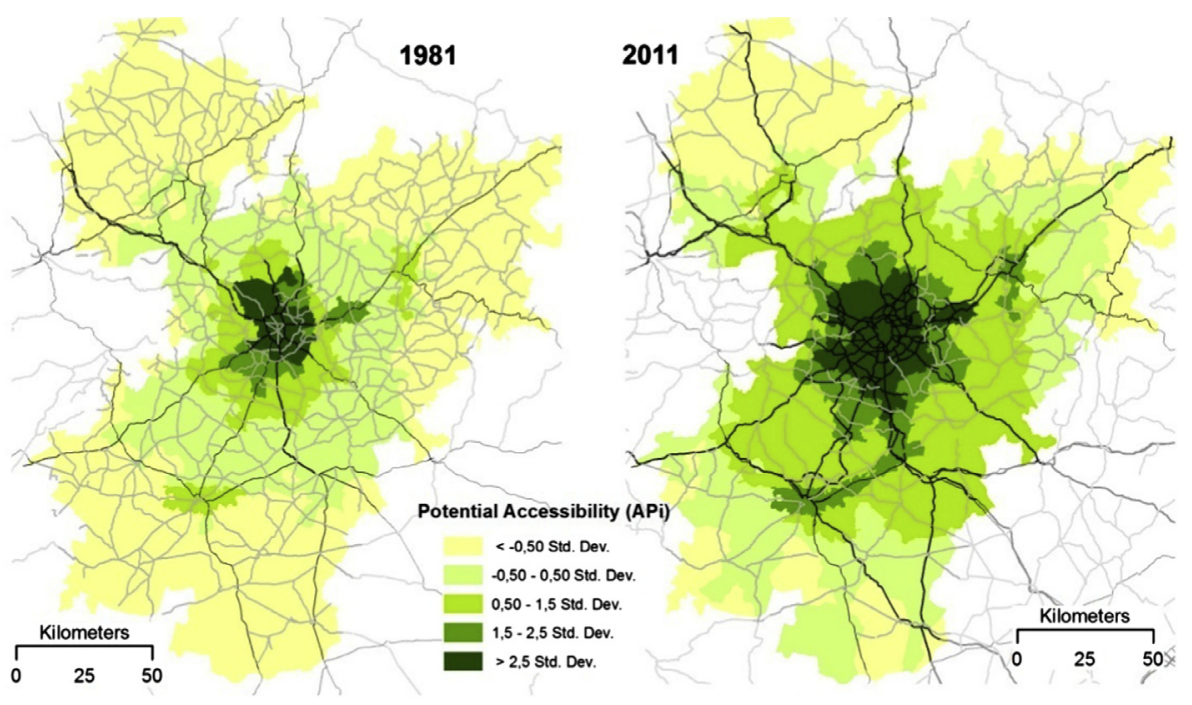

(b) Improvement of interaction, 1981 - 2011

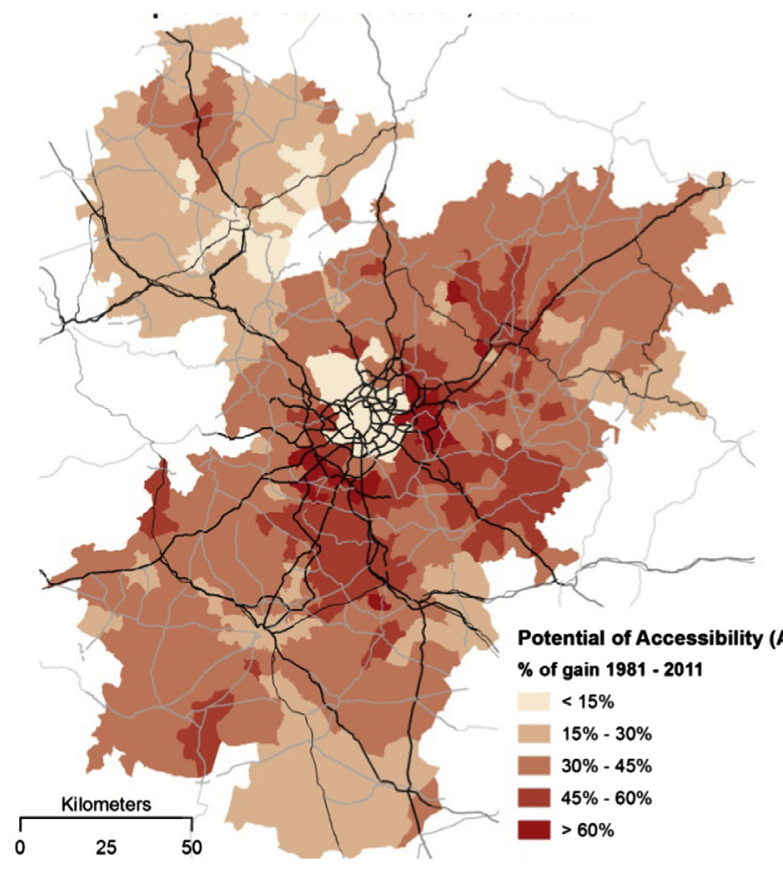

(c) Accessibility and population changes, 1981 - 2011

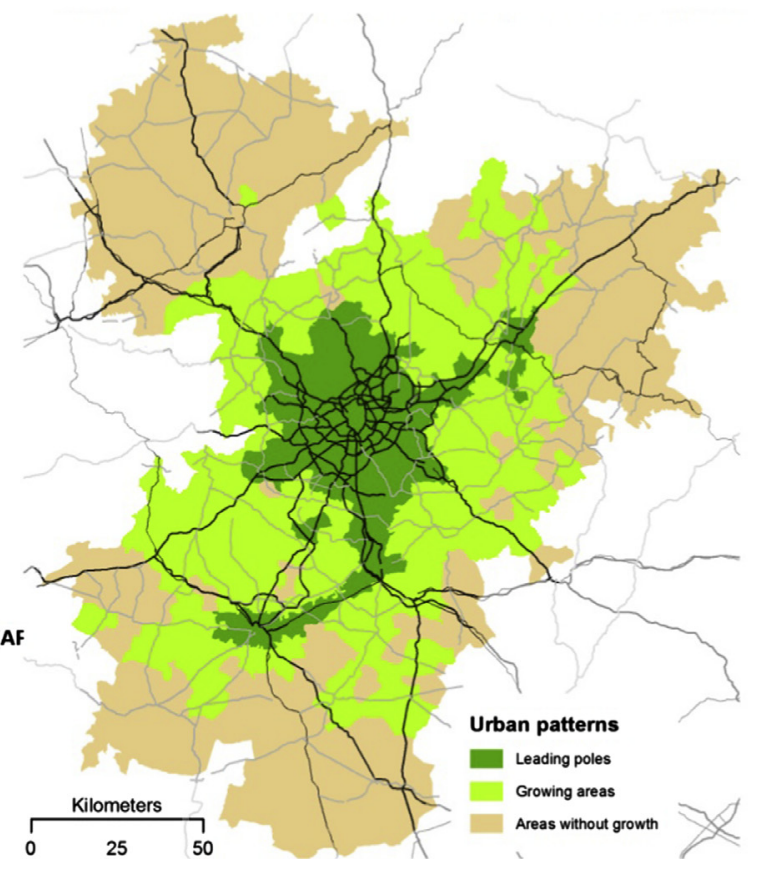

Fig. 4. Potential accessibility $\left(A P_{I}\right)$, distribution, changes and relation with population growth. Years 1981 and 2011.

Segovia). It is noteworthy that the hereby identified leading poles are the same as the ones concluded by other scholars who have considered other methods such as commuting linkages and employment or population concentrations (Gallo et al., 2010; Solís et al., 2012), demonstrating the validity of the hereby proposed accessibility approach in understanding urban patterns. The other two types of municipalities can also be interpreted according to their location and closeness to the metropolitan centre: the first belt (closer to Madrid) characterised by a predominance of growing areas, and those areas without growth located at the second belt, further away from the metropolis.

\subsection{Competition and city-profile}

Lastly, competition effects are assessed. The input sample for this measure is the set of municipalities classified as leading poles by the potential measure analysis (Section 5.2 and Fig. 4c), since they have the highest potential in organising the area and competing for opportunities with each other. The sample consists of 36 municipalities (only $6.5 \%$ of the previous sample), which include Madrid, and extends to two of the three capitals: Guadalajara and Toledo. The required iterative calculation to use the competition measure was undertaken between these 36 municipalities competing for inhabitants and workplaces of the rest of the leading poles.

The outcome of these calculations (Fig. 5) is used to rank these 36 leading poles in regards to their effort for reaching the rest of the sample (Fig. 5a) and vice versa (Fig. 5b). These results are used to assess changes in these rankings between 1981 and 2011 (Fig. 6a and b), and to define a typology of cities in terms of their capability for competing for workplaces and for potential workers (Fig. 6c). 
(a) Capability of residents at each zone to reach workplaces.
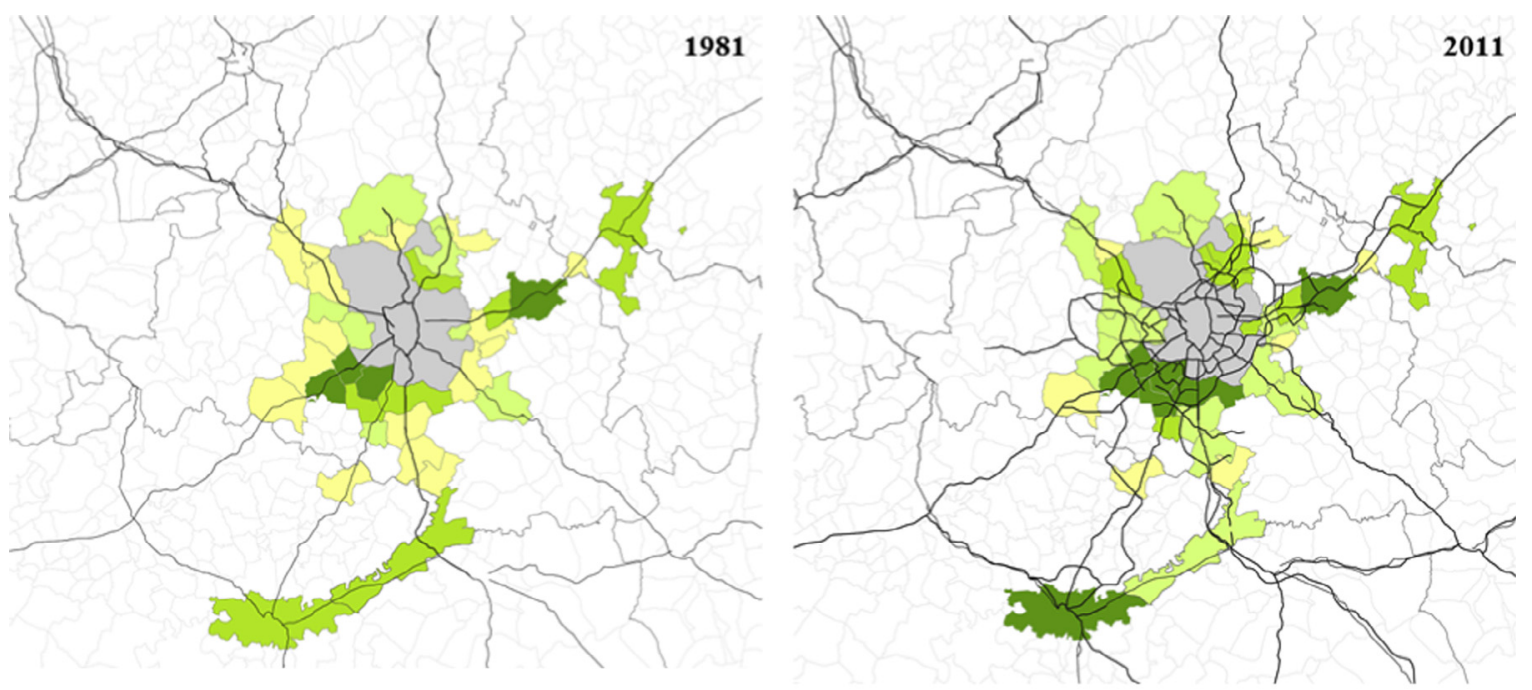

(b) Capability of workplaces to be reached by potential workers.
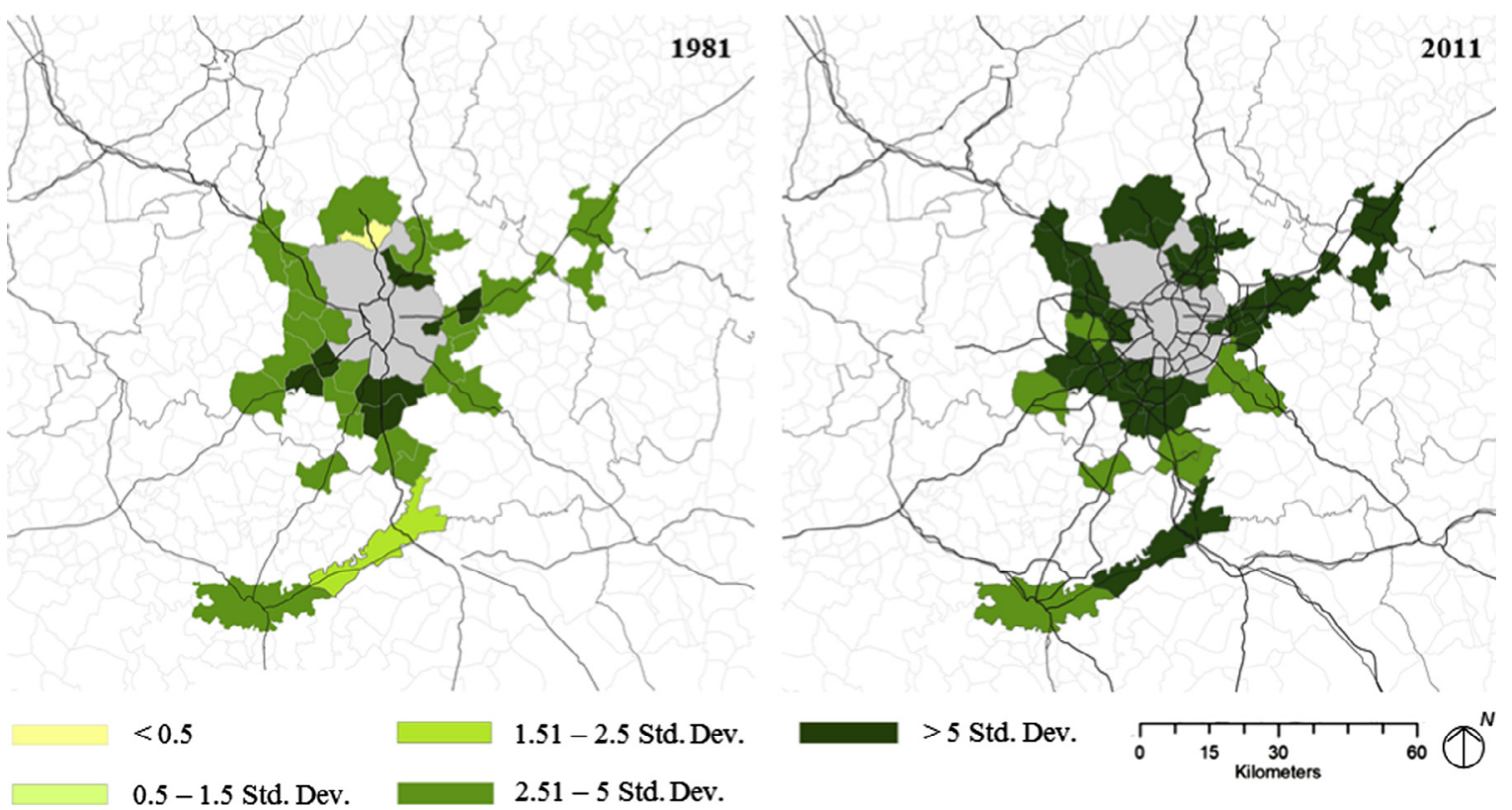

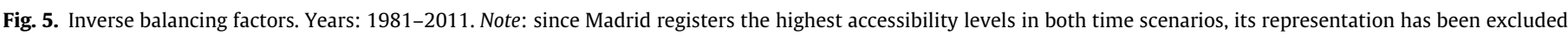
from the previous images to better show how the rest of the sample performs.

In absolute terms, all the leading poles improved their ease for accessing the workplaces of the rest (between 1981 and 2011). Taking into account the 2011 scenario, three main patterns were identified (Fig. 5a):

- The first belt surrounding the metropolis had the greatest competition accessibility levels, especially those located in the southwest sector, favoured by the concentration of high-capacity infrastructures. These municipalities had the highest capabilities for accessing workplaces and competing for available jobs.

- The effort for residents to reach workplaces spread along the main radial corridors with its origin in Madrid.

- Regarding the two peripheral capital cities, both Toledo and Guadalajara reached the highest accessibility levels (as well as municipalities closer to Madrid). In relative terms, the municipality of Toledo improved its ease of access to available jobs and Guadalajara almost maintained it.

Similar outcomes can be drawn by analysing the ease of workplaces to be reached. Favoured by proximity, municipalities close to Madrid had the highest competition accessibility, and Guadalajara is the only peripheral provincial capital with a similar capability for attracting potential workers (Fig. 6b).

Each leading pole is ranked in regards to each competition accessibility measure and scenario, identifying which ones had a better, worse or equal competition accessibility ranking position in 2011 compared to 1981 (Fig. 6a and b). It is important to bear in mind that worse ranking positions do not mean lower accessibility levels in absolute terms, but a worse overall performance among the 36 leading poles in competing for available opportunities. 
(a) Changes of the ranking position for the capability of residents at each zone to reach workplaces (Ai).

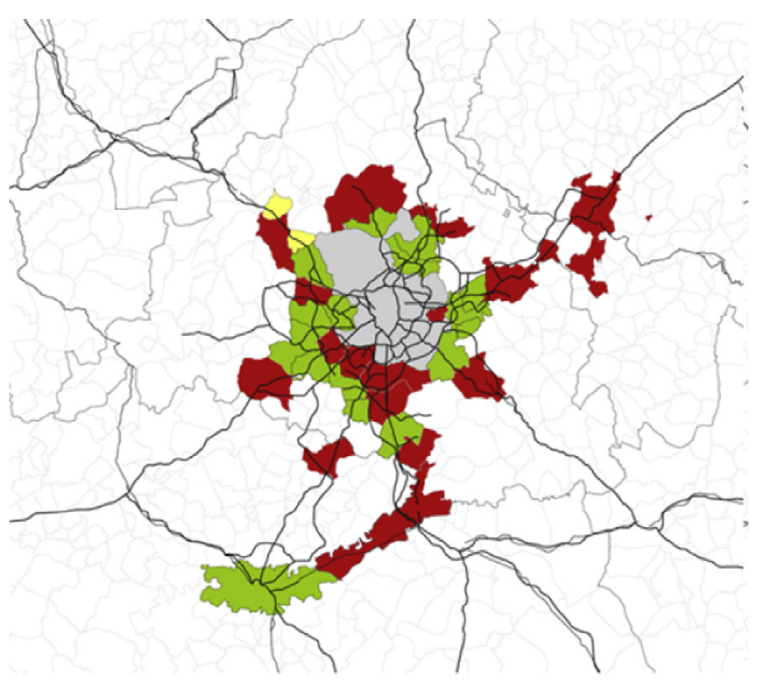

(b) Changes of the ranking position for the capability of workplaces to be reached by potential workers $(\mathbf{B j})$.

No place Rank improvement

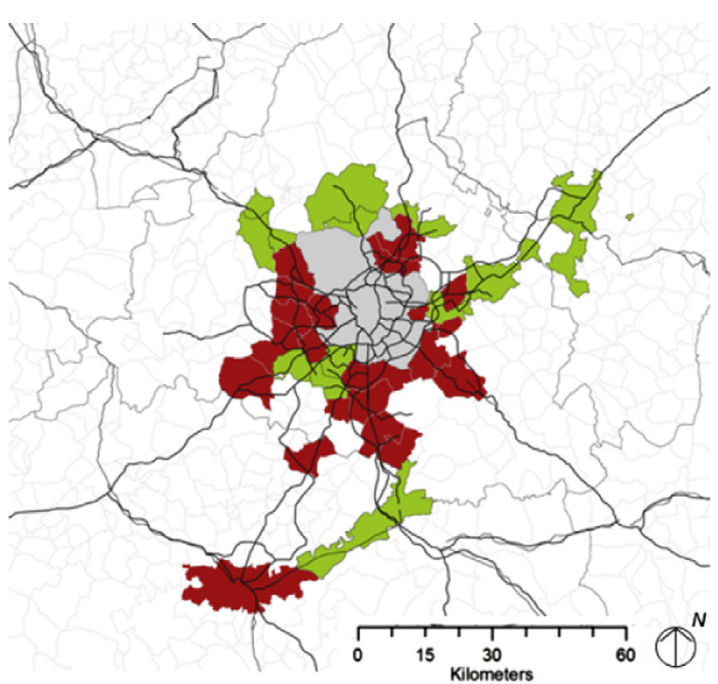

Better ranking position

(c) Types of Leading Poles regarding changes in their accessibility competition ranking positions, 1981 -2011.

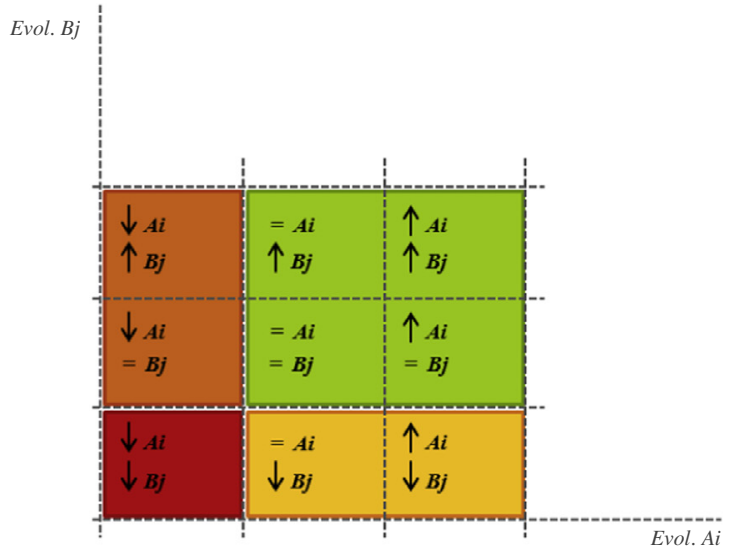

Leading Poles Classification

$\square$ Type A

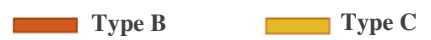

Fig. 6. Ranking position changes and "leading poles" classification.

Consequently, this comparison allows identifying the following city-profiles among the sample (Fig. 6c):

- Type A: Optimal/Competing leading poles, which are characterised by a simultaneous comparative improvement of their attracting and emitting capabilities. These are municipalities that in 2011 had improved or maintained their ranking positions in reaching workplaces (Fig. 6a) and being reached by workers (Fig. 6b).

- Type B: Attracting leading poles which have reinforced their role as employment centres. These municipalities worsened their ranking positions in terms of the ease to reach workplaces (Fig. 6a) but maintained or improved them in terms of being reached by workers (Fig. 6b). The peripheral provincial capital cities are classified under this type.

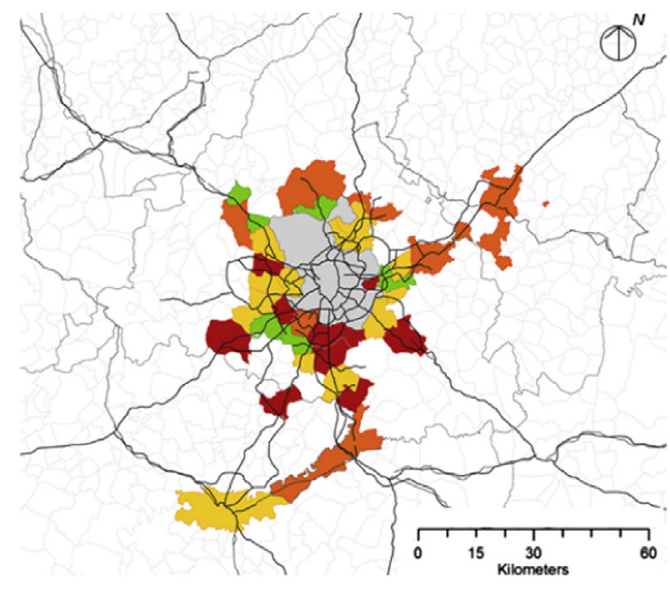

Type D 
and not merely due to its location. Moreover, the outcomes are consistent with previous studies describing the Madrid Metropolitan Region and its residential or employment centres (López, 1999; Solís et al., 2014).

\section{Discussion and conclusions}

This work reinforces the usefulness of accessibility in characterising urban systems that are evolving towards polycentric structures. Overall, transport and road improvements have greatly influenced the enlargement of catchment areas (leading to longer action radius of agglomeration economies) and the reinforcement of accessibility levels in central areas of metropolitan regions (together with a moderated spread along high-capacity corridors). These enlargements and reinforcements, together with an uneven population growth throughout the metropolitan region, have benefited the re-location of economic activities towards a limited number of sub-centres, giving rise to a polycentric urban model.

By providing a methodology based on a road network accessibility analysis, this research sheds light on characterising polycentric metropolitan regions and on differentiating city-profiles among the sub-centres organising these emerging urban structures. Particularly, the proposed combined methodology fosters a comprehensive approach focused on three spatial features of urban systems: integration, interaction and city-profile.

Firstly, metropolitan areas/regions are growing in extension (contour measure), integrating more distant territories and redefining the meaning of closeness (time-space convergence). The analysis of catchment areas also allows understanding the coalescence of labour and residence markets and the integration of distant historic administrative cities (provincial capitals).

Secondly, the capability for interaction (potential measure) demonstrates that some capital cities of adjacent provinces are acquiring similar leading roles than municipalities much closer to the central city, although they are far away from it. Hence, interaction and interdependence are not as closely attached to metric distance.

Thirdly, the competition for jobs and for workers (double-constrained competition measure) shows how certain places with relatively similar features adopt different profiles, specialising in attracting and/or emitting workers and thus reinforcing their role as employment and/or residential centres. This result is of an outstanding relevance since strong differences among leading poles can be perceived by using simple variables (travel time, total amount of workers and jobs). These simple variables can be easily mapped and interpreted to explore the configuration of metropolitan regions' urban systems.

Lastly, while this paper focuses on the road network as a facilitator of metropolitan change, it is important to bear in mind that a complex set of economic and social factors clearly influences the emerging urban polycentric structures. Whilst this work focuses on the morphological approach of polycentrism, its results show a noteworthy level of coincidence with previous analyses using functional approaches (Gallo et al., 2010; Solís et al., 2012). Hence, the method may be considered as a suitable alternative and a reliable tool to recognise changes in the urban system when there are data constraints (e.g. lack of updated mobility/flow information).

In summary, this research confirms the usefulness of accessibility analysis in exploring and evaluating the morphology of urban regions, and in particular, in identifying different profiles among the sub-centres of new polycentric metropolitan regions. Although all these features have been demonstrated for the Madrid Urban Region, the method should be easily extendable to other metropolitan regions.

This research has not been able to differentiate between sectors and types of jobs and inhabitants. Including this further disaggregation would have provided useful additional insights into metropolitan changes, adding a sense of functionality in completion to the morphological approach. Future research should shed light on the above and also on the activities that may be undertaken from each centre within different time thresholds and catchment area scales.

\section{Acknowledgments}

This work is a result of the Research Projects PPII10-0048-643 and TRA2011-28465-C03-01, respectively funded by the Junta de Comunidades de Castilla-La Mancha and the Ministerio de Ciencia y Tecnología (Spain). Also, it has been supported by the Spanish Teaching Fellowship Program. The authors would like to thank the three anonymous referees for their comments and the editor for his insightful feedback. We would also like to thank Rhadameris Gomez for the language revision.

\section{References}

Abadía, X., Pineda, M., 2009. La Congestión en los Corredores de Acceso a Madrid Fundación RACC, Barcelona, <http://imagenes.racc.es/pub/ficheros/adjuntos/ adjuntos_estudio_congestion_webb_jzq_9adadbd7.pdf> (accessed 22.03.13).

Anas, A., Arnott, R., Small, K., 1998. Urban spatial structure. J. Econ. Liter. 36, 1426 1464.

Baum-Snow, N., 2007. Suburbanization and transportation in the monocentric model. J. Urban Econ. 62, 405-423.

Bogart, W.T., Ferry, W.C., 1999. Employment centres in Greater Cleveland: evidence of evolution in a formerly monocentric city. Urban Stud. 36, 2099-2110.

Cerdá, A., 2009. Accessibility: A Performance Measure for Land-use and Transportation Planning in the Montréal Metropolitan Region. Supervised Research Project Report. School of Urban Planning, McGill University, Montreal.

Cheng, J., Bertolini, L., le Clercq, F., Kapoen, L., 2013. Understanding urban networks: comparing a node-, a density- and an accessibility-view. Cities 31, 165-176.

del Cin, A., de Mesones, J., Figueroa, J., 1994. Madrid. City profile. Cities 11 (5), $283-$ 291.

Clark, W.A.V., Kuijpers-Linde, M., 1994. Commuting in restructuring urban regions. Urban Stud. 31, 465-483.

Condeço-Melhorado, A., Gutiérrez, J., Garcia-Palomares, J.C., 2011. Spatial impacts of road pricing: accessibility, regional spillovers and territorial cohesion. Transp. Res. Part A 45, 185-203.

Curtis, C., Scheurer, J., 2010. Planning for sustainable accessibility: developing tools to aid discussion and decision-making. Prog. Plan. 74, 53-106.

EC (European Commission), 1999. ESDP - European Spatial Development Perspective: Towards a Balanced and Sustainable Development of the Territory of the European Union. Office of the Official Publications of the European Community, Luxembourg.

Eiselt, H.A., Laporte, G., 1989. Competitive spatial models. Eur. J. Oper. Res. 39, 231 242.

ESPON, 2004. Potentials for Polycentric Development in Europe. ESPON Project 1.1.1.

Fomento, 2007. Movilia 2006-2007. Encuesta de movilidad, Madrid. <http:// www.fomento.es/NR/rdonlyres/2D1D40A2-3417-4C74-AF3F-D22D3A161F96/ 110679/Movilia20062007.pdf>

Fujita, M., Ogawa, H., 1982. Multiple equilibria and structural transition of nonmonocentric urban configurations. Reg. Sci. Urban Econ. 12, 161-196.

Gallo, M.T., Garrido, R., Vivar, M., 2010. Cambios territoriales en la Comunidad de Madrid: policentrismo y dispersión. EURE 36 (107), 5-26.

Garcia-López, M.A., Muñiz, I., 2010. Employment decentralisation: polycentricity or scatteration? The case of Barcelona. Urban Stud. 47, 3035-3056.

Garcia-López, M.A., 2012. Urban spatial structure, suburbanization and transportation in Barcelona. J. Urban Econ. 72 (2-3), 176-190.

Garreau, J., 1991. EdgeCity: Life on the New Frontier. Doubleday, New York.

Geurs, K.T., Ritsema van Eck, J.R., 2001. Accessibility Measures: Review and Applications. RIVM Report 408505 006. National Institute of Public Health and the Environment, Bilthoven.

Geurs, K.T., van Wee, B., 2004. Accessibility evaluation of land-use transport strategies: review and research directions. J. Transp. Geogr. 12, 127-140.

Giuliano, G., Small, K., 1993. Is the journey to work explained by urban structure? Urban Stud. 30 (9), 1485-1500.

Giuliano, G., Redfearn, C., Agarwal, A., He, S., 2012. Network accessibility and employment centres. Urban Stud. 49 (1), 77-95.

Gordon, P., Richardson, H.W., 1996. Beyond polycentricity. The dispersed metropolis, Los Angeles, 1970-1990. J. Am. Plan. Assoc. 62 (3), 289-295.

Green, N., 2007. Functional polycentricity: a formal definition in terms of social network analysis. Urban Stud. 44 (11), 2077-2103.

Gutiérrez, J., Gómez, G., 1999. The impact of orbital motorways on intrametropolitan accessibility: the case of the Madrid M-40. J. Transp. Geogr. 7 $1-16$.

Hall, P., Pain, K., 2006. The Polycentric Metropolis. Earthscan, London. 
Hansen, W.G., 1959. How accessibility shapes land use. J. Am. Inst. Plan. 25 (1), $73-$ 76.

Harris, B., 2001. Accessibility: concepts and applications. J. Transp. Stat. 4 (2-3), 1530.

Heitkamp, T., 2000. The integration of unplanned towns in the periphery of Madrid: the case of Fuenlabrada. Habit. Int. 24, 213-220.

Helbich, M., Leitner, M., 2009. Spatial analysis of the urban-to-rural migration determinants in the Viennese Metropolitan Area. A transition from sub- to postsuburbia? Appl. Spat. Anal. Policy 2 (3), 237-260.

Holl, A., 2007. Twenty years of accessibility improvements. The case of the Spanish motorway building program. J. Transp. Geogr. 15, 286-297.

Horner, M., 2004. Exploring metropolitan accessibility and urban structure. Urban Geogr. 25 (3), 264-284.

Ingram, D.R., 1971. The concept of accessibility: a search for an operational form. Reg. Stud. 5, 101-107.

Joseph, A.E., Bantock, P.R., 1982. Measuring potential physical accessibility to general practitioners in rural areas: a method and case study. Soc. Sci. Med. 16, 85-90.

Kawabata, M., 2009. Spatiotemporal dimensions of modal accessibility disparity in Boston and San Francisco. Environ. Plan. A 41, 183-198.

Kloosterman, R.C., Musterd, S., 2001. The polycentric urban region: towards a research agenda. Urban Stud. 38, 623-633.

Krugman, P., Venables, T., 1996. Integration, specialization, and adjustment. Eur. Econ. Rev. 40, 959-968.

Lee, B., 2007. "Edge" or "edgeless" cities? Urban spatial structure in U.S. metropolitan areas, 1980 to 2000. J. Reg. Sci. 47, 479-515.

Le Néchet, F., 2012. Urban spatial structure, daily mobility and energy consumption: a study of 34 European cities. Cybergeo: Rev. Eur. Géogr. 580 (accessed 15.03.13).

Limtanakool, N., Dijst, M., Schwanen, T., 2007. A theoretical framework and methodology for characterising national urban systems on the basis of flows of people: empirical evidence for France and Germany. Urban Stud. 44 (11), 2123 2145.

Limtanakool, N., Schwanen, T., Dijst, M., 2009. Developments in the Dutch Urban System on the basis of flows. Reg. Stud. 43 (2), 179-196.

López, R. (Ed.), 1999. La transformación de la ciudad en 20 años de Ayuntamientos democráticos. Ayuntamiento de Madrid, Madrid.

López, E., Gutiérrez, J., Gómez, G., 2008. Measuring regional cohesion effects of large-scale transport infrastructure investments: an accessibility approach. Eur. Plan. Stud. 16 (2), 277-301.

Meijers, E., Romein, A., 2003. Realizing potential: building regional organizing capacity in polycentric urban regions. Eur. Urban Reg. Stud. 10, 173-186.

Meijers, E., Hoekstra, J., Leijten, M., Louw, E., Spaans, M., 2012. Connecting the periphery: distributive effects of new infrastructure. J. Transp. Geogr. 22, 187 198.

Morris, J.M., Dumble, P.L., Wigan, M.R., 1979. Accessibility indicators for transportation planning. Transp. Res. A 13, 91-109.
Patuelli, R., Reggiani, A., Gorman, S.P., Nijkamp, P., Bade, F.J., 2007. Network analysis of commuting flows: a comparative static approach to German data. Networks Spat. Econ. 7 (4), 315-331.

Reggiani, A., Bucci, P., Russo, G., Haas, A., Nijkamp, P., 2011. Regional labour markets and job accessibility in city network systems in Germany. J. Transp. Geogr. 19, 528-536.

Richardson, H.W., 1988. Monocentric vs policentric models: the future of urban economic in regional science. Ann. Reg. Sci. 2, 1-12.

Rodrigue, J.P., Comtois, C., Slack, B., 2009. The Geography of Transport Systems. Routhledge, London.

Roca, J., Moix, M., Arellano, B., 2012. El sistema urbano en España. Scripta Nova XVI(396). <http://www.ub.edu/geocrit/sn/sn-396.htm>.

Schwanen, T., Dieleman, F., Dijst, M., 2001. Travel behaviour in Dutch monocentric and policentric urban systems. J. Transp. Geogr. 9, 173-196.

Scott, A.J., Agnew, J., Soja, E.W., Storper, M., 2001. Global city-regions. In: Scott, A.J. (Ed.), Global City-regions: Trends, Theory, Policy. Oxford University Press, Oxford, pp. 11-32.

Sohn, J., 2005. Are commuting patterns a good indicator of urban spatial structure? J. Transp. Geogr. 13, 306-317.

Solís, E., Ureña, J.M., Ruiz-Apilánez, B., 2012. Transformación del Sistema UrbanoTerritorial en la Región Central de da España Peninsular: La Emergencia de la Región Metropolitana Policéntrica Madrileña, Scripta Nova XVI-(420). <http:// www.ub.edu/geocrit/sn/sn-420.htm> (accessed 22.03.13).

Solís, E., Mohíno, I., Ureña, J.M., 2014. Global metropolitan-regional scale in evolution: metropolitan intermediary cities and metropolitan cities. Eur. Plan. Stud. http://dx.doi.org/10.1080/09654313.2013.878691.

Spiekermann, K., Wegener, M., 1994. The shrinking continent: new time-space maps of Europe. Environ. Plan. B 21, 653-673.

van der Laan, L., 1998. Changing urban systems: an empirical analysis at two spatial levels. Reg. Stud. 32, 235-247.

Van Oort, F.G., Burger, M.J., Raspe, O., 2010. On the economic foundation of the urban network paradigm: spatial integration, functional integration and economic complementarities within the Dutch Randstad. Urban Stud. 47, 725-748.

van Wee, B., Hagoort, M., Annema, J.A., 2001. Accessibility measures with competition. J. Transp. Geogr. 9, 199-208.

Vickerman, R.W., 1974. Accessibility, attraction and potential: a review of some concepts and their use in determining mobility. Environ. Plan. A 6, 675-691.

Weibull, J.W., 1976. An axiomatic approach to the measurement of accessibility. Reg. Sci. Urban Econ. 6, 357-379.

Willigers, J., Floor, H., vanWee, B., 2003. Accessibility in Land-use/Transport Interaction Modeling: LUTI Models as a Method to Determine the Spatial Economics Effects of High-speed Railway Infrastructure. RS-URBIX Research Papers. Utrecht University.

Wilson, A.G., 1967. A statistical theory of spatial distribution models. Transp. Res. 1, 253-269.

Zheng, X.P., 1991. Metropolitan spatial structure and its determinants: a case-study of Tokyo. Urban Stud. 28 (1), 87-104. 